\section{Bond Strength of a Bisphenol- A-Free Fissure Sealant With and Without Adhesive Layer under Conditions of Saliva Contamination}

Késsia Suênia Fidelis de Mesquita-Guimarães ${ }^{1}$, Iliana Ferraz Sabbatini', Cintia Guimarães de Almeida1, Rodrigo Galo², Paulo Nelson-Filho', Maria Cristina Borsatto ${ }^{1}$

\author{
'Department of Pediatric Dentistry, \\ School of Dentistry of Ribeirão \\ Preto, USP - Universidade de São \\ Paulo, Ribeirão Preto, SP, Brazil \\ ${ }^{2}$ Department of Dentistry, UFVJM \\ - Federal University of Valleys \\ of Jequitinhonha and Mucuri, \\ Diamantina, MG, Brazil
}

Correspondence: Késsia Suênia Fidelis de Mesquita, Avenida do Café, s/n, Monte Alegre, 14040904 Ribeirão Preto, SP, Brasil. Tel: +55-16-3602-4114. e-mail: kessiamesquita@gmail.com

\begin{abstract}
Dental sealants are important for prevention of carious lesions, if they have good shear strength. The aim of this study was to evaluate the shear bond strength (SBS) of two sealants to saliva-contaminated and non-contaminated enamel with and without an intermediate adhesive layer underneath the sealant. Ninety flat enamel surfaces from human third molars were randomly assigned to 6 groups $(n=15)$ : $F$ (control): Fluroshield ${ }^{T M}$ sealant; EWB (control): Embrace ${ }^{T M}$ WetBond $^{T M} ; S B / F$ : Single Bond adhesive system + F; SB/ $E W B, s-S B / F$ and s-SB/EWB. In the s-SB/F and s-SB/EWB groups, the acid-etched enamel was contaminated with $0.01 \mathrm{~mL}$ of fresh human saliva for $20 \mathrm{~s}$. Sealant cylinders were bonded to enamel surface with and without an intermediate adhesive system layer. The shear tests were performed using a universal testing machine $(0.5 \mathrm{~mm} / \mathrm{min})$. Data were analyzed statistically by Kruskal-Wallis and Mann-Whitney tests $(\alpha=0.05)$. F presented higher mean SBS than EWB in all experimental conditions. The lowest SBS mean was obtained for EWB on contaminated enamel $(p<0.05)$. In conclusion, an adhesive system layer should be used prior to sealant placement, in both dry and saliva-contaminated enamel. $F$ had the best performance in all experimental conditions. EWB sealant showed very low results, but an adhesive layer underneath the sealant increased its SBS even after salivary contamination.
\end{abstract}

Key Words: fissure sealants, shear strength, Bisphenol-A.

\section{Introduction}

Fissure sealants used as preventive treatment on occlusal surfaces act as an effective mechanical barrier against the accumulation and maturation of biofilm (1), especially if it remains intact and bonded to tooth surface $(2,3)$.

The ideal time for sealant placement is soon after the eruption of permanent molars (4), as newly erupted teeth are less mineralized and more susceptible to acid attack (5). However, sealant placement during this period is challenging because the contact of the tooth with the distal marginal ridge of the gingiva facilitates the contamination of the occlusal surface by moisture or saliva (6), which is the most common cause of sealant failure (2). The microspores produced by acid etching may be partially occluded after a contamination time as short as one second (7). This partial obliteration prevents the ideal formation of resin tags, thus weakening sealant retention (8).

Conventional pit and fissure sealants are extremely sensitive to moisture due to their hydrophobic nature and thus require a clean, dry and etched enamel surface during placement (9). In addition, resin-based materials, although more and more popular like composite resins and pit and fissure sealants, have caused concern due to the presence of 2,2-bis(4-hydroxyphenyl)propane (Bisphenol A - BPA) (10). BPA is a plastic used in the fabrication of several other products, including bottles, baby bottles, detergents, food packing and its derivatives, may present hazard to health (11).

Some studies found that BPA could induce changes in various mechanisms and physiological processes, among which early puberty in females and feminization in male at very low levels (12), high-risk breast and prostate cancer (13), calcium influx induction, which leads to release of prolactin (14), development of hyperglycemia, insulin tolerance and diabetes (15), cardiovascular disease (10), abnormal concentration of Y-glutamyl liver enzymes and alkaline phosphatase (16), according to the switching of the $\beta$-pancreatic cells (18), dysfunction of thyroid hormone production (18), increase of reactive oxygen species (19), which are implicated in oxidative stress mechanism and over-regulation of cAMP response element binding protein, which inhibits apoptosis (20).

Although the amount and duration of systemic BPA absorption that can produce adverse effects has not yet been established $(11,21)$, it is known that BPA is released from dental resinous materials by the salivary enzymatic hydrolysis of its derivatives and it is detectable in saliva for up to $3 \mathrm{~h}$ after material placement in the mouth (21). Residual (uncured) BPA can be removed from the resin or sealant through chewing attrition or be degraded chemically or mechanically, and may be absorbed systemically $(10,22)$.

The successful clinical use of fissure sealants is attributed to their retention, resistance to wear and 
capacity to maintain an adequate seal on tooth surface (1). Previous studies have reported increased bond strengths after application of an adhesive layer between sealant and contaminated $(4,23-25)$ and non-contaminated $(23)$ etched enamel, due to its hydrophilic property (24). A BPAfree fissure sealant moisture-tolerant product has been introduced under the trade name Embrace ${ }^{\mathrm{TM}}$ WetBond ${ }^{\mathrm{TM}}$ (EWB; Pulpdent Corporation, Watertown, MA, USA), which good marginal adaptation in pits and fissures (22) and reduction of microbial attachment on sealant surface (26).

Because research is limited to these tests and there is lack of information on the retention of EWB under dry conditions and salivary contamination to prove its effectiveness. The aim of this study was to evaluate the shear bond strength (SBS) of a EWB BPA-free sealant to saliva-contaminated and non-contaminated enamel with or without use of an intermediate adhesive layer underneath the sealant. The hypothesis was that there is no significant difference among the experimental conditions.

\section{Material and Methods}

After research protocol approval by the institutional Ethics Committee (Process \#2010.1.539.58.0), freshly extracted sound human third molars were cleaned from calculus and root-adhered debris and examined under a $\times 20$ magnifier to discard those with cracks and structural defects.

Sample size calculation was performed before the beginning of the study using the $\mathrm{G}$ Power 3.1.7 Version (Franz Faul, Universität Kiel, Germany) software for Windows XP. Expecting the minimum correlation of 0.60 with 0.80 power, 0.801 actual power and alpha of 0.05 and one-sided test, the minimum sample size was 15 samples.

Forty-five teeth were selected for the study and stored in $0.9 \%$ saline with $0.4 \%$ sodium azide at $4{ }^{\circ} \mathrm{C}$. Prior to use, the teeth were washed in running water to eliminate storage solution residues. Roots were cut transversally $2 \mathrm{~mm}$ below the cementoenamel junction, crowns were bisected buccolingually and the resulting halves were embedded in polyester resin $(2.1 \mathrm{~cm}$ diameter and $1.1 \mathrm{~cm}$ high). After resin polymerization, the mesial and distal enamel surfaces were ground wet with \#320- to 400-grit silicon carbide (SiC) papers (Buehler Ltd., Lake Bluff, IL, USA), in a low-speed polishing machine (Aropol 2V; Arotec S/A, São Paulo, SP, Brazil). The specimens were hand polished with wet \#600grit $\mathrm{SiC}$ paper and cleaned with pumice slurry to obtain 90 flat, smooth test surfaces. The bonding site was delimited with an adhesive tape piece with a 3-mm-diameter central hole. The following materials were used: Fluroshield ${ }^{\mathrm{TM}}$ sealant (F; Dentsply/Caulk, Milford, DE, USA), Embrace ${ }^{\mathrm{TM}}$ WetBond $^{\mathrm{TM}}$ (EWB, Pulpdent), Adper Single Bond adhesive system ( $\mathrm{SB} ; 3 \mathrm{M}$ ESPE, St. Paul, MN, USA). The 90 test specimens randomly assigned to 6 groups ( $n=15)$, as follows: $F$ (control), EWB (control), SB/F, SB/EWB, s-SB/F, s-SB/EWB. In all groups, the enamel surfaces were etched with a $37 \%$ phosphoric acid gel (Scotchbond ${ }^{T M}$ Etchant; 3M ESPE).

The specimens were individually fixed in a metallic clamping device and the test surfaces were pressed against a split polytetrafluoroethylene jig to provide a cylindrical cavity ( $4 \mathrm{~mm}$ high $\times 3 \mathrm{~mm}$ diameter) coincident with the delimited enamel bonding site. In groups s-SB/F and s-SB/ $E W B$, acid-etched enamel was contaminated with $0.01 \mathrm{~mL}$ of fresh human saliva from a healthy donor for $20 \mathrm{~s}$ and the enamel surface was not dried. Sealant was inserted into the jig in two increments (2 $\mathrm{mm}$ high $\times 3 \mathrm{~mm}$ diameter), polymerized for $20 \mathrm{~s}$ each. As the cavity was filled, the specimen was released from the jig and clamping device, resulting in a sealant cylinder ( $4 \mathrm{~mm} \times 3 \mathrm{~mm}$ ) bonded to the enamel surface.

In groups $S B / F, S B / E W B$, s-SB/F and s-SB/EWB, the adhesive system was used before sealant placement. Disposable microbrush tips were used to avoid excess and pooling of adhesive along the edges of the adhesive tape, which could affect tension distribution during the shearing test and the validity of results. The adhesive system and the sealants were light-cured for $10 \mathrm{~s}$ and $20 \mathrm{~s}$, respectively, with a halogen light-curing unit (XL 3000; 3M/ESPE) with $450 \mathrm{~mW} / \mathrm{cm}^{2}$ output, as measured with a curing radiometer (Demetron Research Corp., Danbury, CT, USA).

After $24 \mathrm{~h}$ storage in distilled water at $37^{\circ} \mathrm{C}$, SBS was measured using a knife-edge blade in a universal testing machine (MEM 2000; EMIC Ltda, São José dos Pinhais, PR, Brazil) with a $50 \mathrm{kgf}$ load cell at crosshead speed of 0.5 $\mathrm{mm} / \mathrm{min}$. The fractures were analyzed under a stereoscopic microscope (Nikon Instrument Group Inc. Melville, NY, USA) with 40x magnification in order to determine the types of fracture: adhesive, at the enamel interface/sealant or adhesive system; cohesive, in the body of the sealant or enamel, keeping an intact interface; and mixed when occurred disruption of the adhesive bond and the material or the substrate at the same time.

Means in MPa and standard deviations were calculated and analyzed regarding their distribution and homogeneity. Data were analyzed statistically by Kruskal-Wallis and Mann-Whitney tests using SPSS (SPSS 12.0 for Windows Inc., Chicago, IL, USA). Significance level was set at 5\%.

\section{Results}

The F group presented significantly higher SBS $(p<0.05)$ than the EWB group in all experimental conditions. Comparing the groups sealed with Fluroshield ${ }^{T M}$, the SB/F group had the highest bond strength $(p<0.05)$. The SB/EWB group presented significantly higher SBS than the EWB group, which had the lowest SBS of all groups $(p<0.05)$. The use of an intermediate adhesive prior to application 
of Fluroshield ${ }^{\mathrm{TM}}$ increased significantly the SBS to dry enamel, which did not occur in the presence of salivary contamination. The SBS of EWB to both contaminated and non-contaminated enamel increased significantly when the sealant was combined with the adhesive system (Table 1).

Failure mode analysis revealed a predominance of cohesive failures in SB/F (40\%) and SB/EWB (66.6\%) groups. Adhesive failures were prevalent in EWB (60\%) and s-SB/F (53.3\%) groups and mixed failures in $\mathrm{F}$ and $\mathrm{s}-\mathrm{SB} / \mathrm{EWB}$ groups, with $40 \%$ and $60 \%$, respectively (Fig. 1).

\section{Discussion}

The effectiveness of sealants as caries-preventive agents depends mainly on an adequate bonding of the sealant to the tooth surface and its complete retention on the tooth (9). Sealant retention is often assessed by shear strength tests and the results are considered reliable and effective in comparative studies to determine the adhesion of materials to tooth structure (27).

The resin-based sealant Fluroshield ${ }^{\mathrm{m}}$ is the gold standard in sealant research due to its excellent shear test results (4), since the average range of bond strength was is accepted to be 5.9 to $7.8 \mathrm{MPa}$ clinically and $4.9 \mathrm{MPa}$ for laboratory performances (24). However, there are few studies testing EWB $(9,22,27,28)$ and none has assessed sealant retention against shearing forces. Therefore a comparative analysis with the results of the present study cannot be done. Base don the findings, the null hypothesis could not be accepted.

Studies have shown that the SBS between sealant and enamel surface decreases significantly under conditions of salivary contamination (4). Because of the high enamel reactivity induced by phosphoric acid etching, even minute exposures to saliva, as brief as $1 \mathrm{~s}$, could be sufficient to create a pellicle that partially occludes the enamel

Table 1. Shear bond strength means (MPa) of the fissure sealants with and without an intermediate adhesive layer under dry and salivacontamination conditions

\begin{tabular}{lc}
\hline Group & Means $( \pm$ SD) MPa \\
\hline F & $9.55 \pm 0.78 \mathrm{~b}$ \\
EWB & $1.51 \pm 0.21 \mathrm{~d}$ \\
$\mathrm{SB} / \mathrm{F}$ & $12.95 \pm 0.63 \mathrm{a}$ \\
$\mathrm{SB} / \mathrm{EWB}$ & $3.42 \pm 0.35 \mathrm{c}$ \\
s-SB/F & $10.42 \pm 0.65 \mathrm{~b}$ \\
s-SB/EWB & $3.14 \pm 0.24 \mathrm{c}$ \\
\hline
\end{tabular}

F (control): Fluroshield ${ }^{\mathrm{TM}}$ sealant; EWB (control): Embrace $^{\mathrm{TM}}$ WetBond $^{\mathrm{TM}}$; $\mathrm{SB} / \mathrm{F}$ : Single Bond adhesive system + Fluroshield ${ }^{\mathrm{TM}}$ sealant; SB/EWB: Single Bond + Embrace ${ }^{\mathrm{TM}}$ WetBond ${ }^{\mathrm{TM}} ; \mathrm{s}-\mathrm{SB} / \mathrm{F}$ : salivary contamination + Single Bond + Fluroshield ${ }^{\mathrm{TM}}$; s-SB/EWB: salivary contamination + Single Bond + Embrace $^{\mathrm{TM}}$ WetBond $^{\mathrm{TM}}$. Different letters indicate statistically significant difference among the groups $(\mathrm{p}<0.05)$. pores, causing ultrastructural alterations and preventing formation of the resin tags responsible for mechanical retention (8). The use of adhesive systems underneath sealant restorations has been suggested to minimize the deleterious effects of salivary contamination to adhesion (4). It was significantly observed only for EWB sealant, which had a similar result when associated to adhesive without contamination. Fluroshield ${ }^{\mathrm{TM}}$ showed higher SBS means when it was associated with adhesive systems without contamination. This is likely due to the great capacity of single-bottle adhesives to flow deeply into capillary-like spaces of the etched enamel surface and produce an optimal resin tag penetration and enhanced adhesion (4).

The manufacturer states that EWB incorporates di-, triand multi-functional acrylate monomers into a hydrophilic, resin acid-integrating network. The sealant is activated in presence of moisture and is recommended for placement on slightly moist acid-etched enamel surfaces, which can form micromechanical and chemical bonds to slightly moist surfaces (9). When activated, EWB is acidic, but the cured material has low water solubility and a neutral $\mathrm{pH}$ (22). This could be the reason why EWB showed better results with the adhesive system. The hydrophilic monomers in the contemporary adhesive systems are known to increase the surface wetting and resin penetration (24).

Although EWB may offer lower polymerization shrinkage due to the absence of BPA (22), epoxy resins are known to have an outstanding adhesive quality (29), which could be an explanation for the remarkably low adhesion of EWB even to non-contaminated enamel, which had $60 \%$ of adhesive fractures. Thus, on one hand, BPAfree resinous dental materials may be advantageous for avoiding potential toxic effects to the patients (25), but on the other hand. The absence of BPA may affect negatively the adhesion of materials to dental tissues (11). In previous studies, EWB showed better adaptation compared to conventional sealants $(9,28)$. In this study, EWB presented

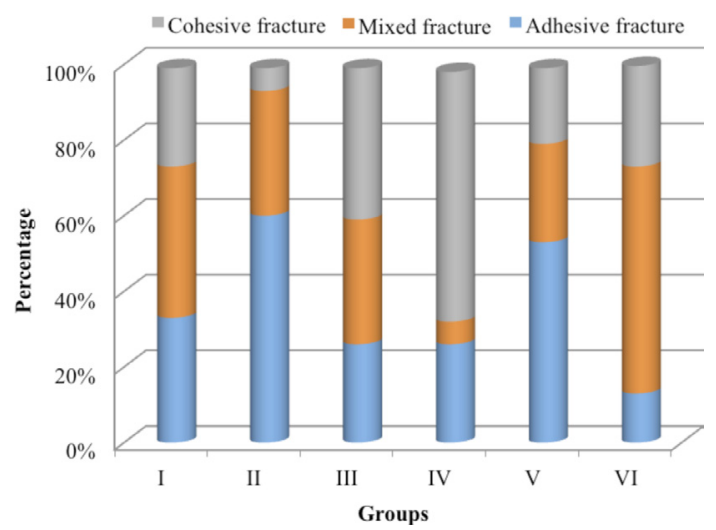

Figure 1. Failure mode distribution in the groups after shearing test. 
the lowest SBS means when used strictly following the manufacturer's instructions, compared to Fluroshield ${ }^{\mathrm{TM}}$. Although this study has not evaluated the morphology of the fissures, it may have affected the outcome, since it was found that cracks in $\mathrm{V}$ and $\mathrm{U}$ format featured the best penetrations and adaptations (28). Third molars were used in this research, which have varied occlusal anatomy.

Further laboratory studies are required to confirm and explain the results of the present study as well as testing other mechanical properties of EWB to provide the scientific basis for its clinical indication. The combination of EWB with adhesive systems could improve the mechanical properties of the sealant with the benefit of not releasing BPA; however, in this study, the EWB did not produce good results for shear strength under any of the tested conditions.

It may be concluded that an adhesive system layer should be used prior to sealant placement, in both dry and saliva-contaminated enamel. $F$ had the best performance in all experimental conditions.

\section{Resumo}

Selantes dentários são importantes para a prevenção de lesões de cárie desde que tenham boa resistência ao cisalhamento. 0 objetivo deste trabalho foi avaliar a resistência ao cisalhamento (SBS), de dois selantes em esmalte contaminado e não contaminado com saliva, com e sem uma camada adesiva intermediária sob o selante. Noventa superficies de esmalte de terceiros molares humanos foram planificadas e divididas aleatoriamente em 6 grupos $(n=15)$ : $F$ (controle): selante Fluroshield ${ }^{\text {Tw }}$; EWB (controle): Embrace $^{\text {TM }}$ WetBond ${ }^{\mathrm{TM}} ; \mathrm{SB} / \mathrm{F}$ : sistema adesivo Single Bond $+\mathrm{F} ; \mathrm{SB} / \mathrm{EWB}$, s-SB/F and s-SB/EWB. Nos grupos s-SB/F e s-SB/EWB, a contaminação do esmalte condicionado foi obtida com $0,01 \mathrm{~mL}$ de saliva humana fresca durante $20 \mathrm{~s}$. Cilindros de selante foram colocados sobre a superficie do esmalte com e sem uma camada de sistema adesivo intermediária. Os ensaios de cisalhamento foram realizados utilizando uma máquina universal de ensaios $(0,5 \mathrm{~mm} / \mathrm{min})$. Os dados foram analisados estatisticamente pelo teste de Kruskal-Wallis e Mann-Whitney $(\alpha=0,05)$. F apresentou valores médios de SBS maiores do que EWB em todas as condições experimentais. 0 menor valor médio de SBS foi obtido pelo EWB em esmalte contaminado $(p<0,05)$. Em conclusão, uma camada de sistema de adesivo deve ser utilizada antes da colocação do selante, tanto em superficie seca quanto contaminada por saliva. $F$ teve 0 melhor desempenho em todas as condições experimentais. 0 selante EWB apresentou resultados insatisfatórios, porém o uso de uma camada adesiva abaixo do selante aumentou sua SBS, mesmo após a contaminação salivar.

\section{References}

1. Prabhakar AR, Murthy SA, Sugandhan S. Comparative evaluation of the length of resin tags, viscosity and microleakage of pit and fissure sealants - an in vitro scanning electron microscope study. Contemp Clin Dent 2011;2:324-330.

2. Panigrahi $A$, Srilatha KT, Panigrahi RG, Mohanty $S$, Bhuyan SK, Bardhan D. Microtensile bond strength of Embrace WetBond hydrophilic sealant in different moisture contamination: an in-vitro study. J Clin Diagn Res 2015;9:ZC23-ZC25.

3. Simonsen RJ, Neal NC. A review of the clinical application and performance of pit and fissure sealants. Aust Dent J 2011;56:45-58.

4. Gomes-Silva JM, Torres CP, Contente MMMG, Oliveira MAHM, Palma-Dibb RG, Borsatto MC. Bond strength of a pit-and-fissure sealant associated to etchand-rinse and self-etching adhesive systems to saliva-contaminated enamel: individual vs. simultaneous light curing. Braz Dent J 2008;19:341-347.

5. Waggoner WF. Managing occlusal surfaces of young permanent molars. J Am Dent Assoc 1991;122:72-76.
6. Locker D, Jokovic A, Kay EJ. Prevention. Part 8: The use of pit and fissure sealants in preventing caries in the permanent dentition of children. Br Dent J 2003;195:375-378.

7. Silverstone LM, Hicks MJ, Featherstone MJ. Oral fluid contamination of etched enamel surfaces: an SEM study. J Am Dent Assoc 1985;110:329-332.

8. Hormati AA, Fuller JL, Denehy GE. Effects of contamination and mechanical disturbance on the quality of acid-etched enamel. J Am Dent Assoc 1980;100:34-38.

9. Khatri SG, Samuel SR, Acharya S, Patil S, Madan K. Retention of moisturetolerant and conventional resin-based sealant in six- to nine-year-old children. Pediatr Dent 2015;37:366-370.

10. Lang IA, Galloway TS, Scarlett A, Henley WE, Depledge M, Wallace RB, et al.. Association of urinary bisphenol A concentration with medical disorders and laboratory abnormalities in adults. J Am Dent Assoc 2008;300:1303-1310.

11. Fleisch AF, Sheffield PE, Chinn C, Edelstein BL, Landrigan PJ. Bisphenol A and related compounds in dental materials. Pedriatics 2010;126:760-768.

12. Timms BG, Howdeshell KL, Barton L, Bradley S, Richter CA, vom Saal FS. Estrogenic chemicals in plastic and oral contraceptives disrupt development of the fetal mouse prostate and urethra. Proc Natl Acad Sci USA 2005;102:7014-7019.

13. Sasco AJ. Epidemiology of breast cancer: an environmental disease? APMIS 2001;109:321-332.

14. Palanza P, Howdeshell KL, Parmigiani S, vom Saad FS. Exposure to a low dose of bisphenol A during fetal life or in adulthood alters maternal behavior in mice. Environ Health Perspect 2002;110 Suppl 3:415-422.

15. Alonso-Magdalena P, Morimoto S, Rípoli C, Fuentes E, Nadal A. The estrogenic effect of bisphenol $A$ disrupts the pancreatic $\beta$-cell function in vivo and induces insulin resistance. Environ Health Perspect 2006;114:106-112.

16. Bindhumol V, Chitra KC, Mathur PP. Bisphenol A induces reactive oxygen species generation in the liver of male rats. Toxicology 2003;188:117-124.

17. Ropero $A B$, Alonso-Magdalena $P$, Garcia-Garcia $E$, Ripoli $C$, Fuentes $E, N a d a l$ A. Bisphenol A disruption of the endocrine pancreas and blood glucose homeostasis. Int J Androl 2008;31:194-200.

18. Moriyama $K$, Tagami $T$, Akamizu $T$, Usui $T$, Saijo $M$, Kanamoto $N$, et al.. Thyroid hormone action is disrupted by bisphenol $\mathrm{A}$ as an antagonist. J Clin Endocrinol Metab 2002;87:5185-5190.

19. Ooe $H_{1}$ Tkahiro $T$, Iguchi-Ariga SMM, Ariga $H$. Induction of reactive oxygen species by bisphenol $A$ and abrogation of bisphenol $A$ induced cell injury by DJ-I. Toxicol Sci 2005;88:114-126.

20. Quesada I, Fuentes E, Viso-León MC, Soria B, Ripoli C, Nadal A. Low doses of the endocrine disruptor bisphenol $A$ and the native hormone $17 \beta$-estradiol rapidly activate transcription factor CREB. FASEB J 2002;16:1671-1673.

21. Kloukos D, Pandis N, Eliades T. In vivo bisphenol-A release from dental pit and fissure sealants: a systematic review. J Dent 2013;41:659-667.

22. Kane B, Karren J, Garcia-Godoy C, Garcia-Godoy F. Sealant adaptation and penetration into occlusal fissures. Am J Dent 2009;22:89-91.

23. Asselin $M-E_{1}$ Sitbon $W_{1}$ Fortin D, Abelardo L, Rompre PH. Bond strength of a sealant to permanent enamel: evaluation of 3 application protocols. Pediatr Dent 2009;31:323-328.cs

24. Feigal RJ, Musherure P, Gillespie B, Levy-Polack M, Quelhas I, Hebling J. Improved sealant retention with bonding agents: a clinical study of twobottle and single-bottle systems. J Dent Res 2000;79:1850-1856.

25. Kang JH, Kondo F, Katayama Y. Human exposure to bisphenol A. Toxicology 2006;226:79-89.

26. Sadeghi M. An in vitro microleakage study of class $V$ cavities restored with a new self-adhesive flowable composite resin versus different flowable materials. Dent Res J 2012;9:460-465.

27. Eliades A, Birpou E, Eliades T, Eliades G. Self-adhesive restoratives as pit and fissure sealants: A comparative laboratory study. Dent Mater 2013;29:752762.

28. Iyer RR, Gopalakrishnapillai AC, Kalantharakath T. Comparisons of in vitro penetration and adaptation of moisture tolerant resin sealant and conventional resin sealant in different fissure types. Chin J Dent Res 2013;16:127-136.

29. Bowen RL. Use of epoxy resins in restorative materials. J Dent Res 1956;35:360-369. 